\title{
ATRIBUTOS MECÂNICOS E EROSÃO POR SALPICAMENTO EM AMOSTRAS DE LATOSSOLO VERMELHO-AMARELO SOB EFEITO DE VINHAÇA ${ }^{1}$
}

\author{
Soil mechanical attributes and splash erosion on samples of red-yellow \\ latosol influenced by sugarcane vinasse ${ }^{1}$ \\ Luiz Gustavo Fernandes Julião², José Maria de Lima³, Moacir de Souza Dias Júnior³, \\ Geraldo César de Oliveira ${ }^{3}$, Bruno Teixeira Ribeiro ${ }^{4}$, Ciro Augusto de Souza Magalhães ${ }^{3}$
}

\begin{abstract}
RESUMO
Objetivou-se, neste trabalho, quantificar o efeito da vinhaça no comportamento compressivo e nos atributos mecânicos, como consistência, umidade ótima de compactação e densidade máxima, de um Latossolo Vermelho-Amarelo (LVA); avaliar o efeito da vinhaça e do estado de compactação no salpicamento de partículas, da região de Lavras, MG. A vinhaça foi proveniente de um alambique de cachaça artesanal. Foram coletadas amostras deformadas e indeformadas nas profundidades de 0 a $3 \mathrm{~cm}$ e 60 a $63 \mathrm{~cm}$. As amostras deformadas destinaram-se à caracterização do solo, determinação dos limites de consistência e realização do ensaio de Proctor Normal, após a incubação do material com vinhaça. As amostras indeformadas foram saturadas com vinhaça ou água destilada (controle), por 48 horas e destinaram-se aos ensaios de compressibilidade e resistência ao salpicamento, usando-se um minisimulador de chuvas. A vinhaça alterou os limites de consistência das camadas estudadas. Para a camada de $0-3 \mathrm{~cm}$ a vinhaça reduziu a faixa friável e para a camada 60-63 cm aumentou. Para ambas as camadas, a vinhaça aumentou a $D_{\text {máx }}$ e reduziu a $U_{\text {ótima }}$. As camadas $0-3 \mathrm{~cm}$ e 60-63 cm, independentemente do tratamento com vinhaça, apresentaram a mesma capacidade suporte de carga. O estado de compactação das amostras influenciou a erosão por salpicamento. $\mathrm{O}$ aumento da pressão aplicada sobre as amostras resultou no aumento da quantidade de material salpicado. Na camada $60-63 \mathrm{~cm}$, o tratamento com vinhaça reduziu a quantidade de material salpicado com o aumento da pressão aplicada, notadamente com as amostras na capacidade de campo.
\end{abstract}

Termos para indexação: Compressibilidade, capacidade suporte de carga, estrutura do solo, salpicamento, Proctor Normal.

\begin{abstract}
The objective of this study was to quantify the effect of plonk on compressive behavior and mechanical attributes such as consistency, optimum moisture for compaction and maximum density of a Red-Yellow Latosol (Oxisol) to evaluate the effect of plonk and compaction state in splashed particles, from Lavras (MG) region. The plonk was obtained from an artisanal sugarcane brandy alembic. Undisturbed and disturbed soil samples were collected at 0 to $3 \mathrm{~cm}$ and 60 to $63 \mathrm{~cm}$ depths. Disturbed soil samples were used for soil characterization, determination of consistence limits and Normal Proctor essay after material incubation with plonk. Undisturbed soil samples were saturated with plonk or distilled water (control) during 48 hours for testing the compressibility and resistance to splash by using simulated rainfall. The plonk altered the consistence limits of studied layers. For the $0-3 \mathrm{~cm}$ layer, the plonk reduced the friable range, and for the $60-63 \mathrm{~cm}$ layer the effect was in the opposite direction. For both layers, the plonk increased $\mathrm{D}_{\max }$ and decreased $\mathrm{U}_{\text {optimum }}$. Regardless of the plonk treatment, both layers presented the same load support capacity. The compaction degree of samples influenced the splash erosion. The increase of the applied pressure over the samples resulted in increase of splash material quantity. At the $60-63 \mathrm{~cm}$ layer, the plonk treatment reduced the splash material quantity by increasing the applied pressure, mainly when the samples were at field capacity.
\end{abstract}

Index terms: Soil compressibility, load support capacity, soil structure, splash erosion, Proctor Test.

(Recebido em 23 de outubro de 2009 e aprovado em 28 de julho de 2010)

\section{INTRODUÇÃO}

O Brasil é o maior produtor mundial de álcool e o único a implantar, em larga escala, um combustível alternativo aos derivados do petróleo, tendo hoje o reconhecimento mundial dessa iniciativa (Andrietta et al., 2007; Goldemberg, 2008). Outra atividade bastante intensa é a produção de aguardente ("cachaça"), segunda bebida alcoólica mais consumida no país (Cardoso, 2006).
Concomitantemente a essas atividades, aumenta-se a produção de vinhaça, principal resíduo do processo de industrialização da cana-de-açúcar produzida à razão de 12 a 13 litros, para cada litro de álcool ou cachaça (Freire $\&$ Cortez, 2000). Umas das alternativas de sua reutilização é a disposição em solos como fertilizante (Freire \& Cortez, 2000).

Os efeitos da vinhaça sobre os atributos químicos, físicos e biológicos do solo são bem conhecidos, contudo, pouco é conhecido de seus efeitos em atributos mecânicos

${ }^{1}$ Parte da Dissertação de Mestrado do primeiro autor apresentada à Universidade Federal de Lavras/UFLA

${ }^{2}$ Universidade Estadual de Campinas/UNICAMP - Faculdade de Engenharia Agrícola - Avenida Santa Izabel - 1125 - Bloco F1 - Bairro Barão Geraldo Cx. P. 6011 - Campinas, SP - luizgustavo.fernandesjuliao@gmail.com

3Universidade Federal de Lavras/UFLA - Departamento de Ciência do Solo/DCS - Lavras, MG

${ }^{4}$ Universidade Federal de Uberlândia/UFU - Instituto de Ciências Agrárias/ICIAG - Uberlândia, MG 
de solos, como seus limites de consistência, comportamento compressivo, capacidade suporte de carga, umidade ótima de compactação e densidade máxima. Freire \& Aguiar (1993) constataram que a vinhaça alterou os parâmetros densidade máxima e umidade ótima de compactação em dois solos de texturas distintas, um arenoargiloso e outro argilo-siltoso. Com relação aos limites de consistência de dois solos (um arenoso e outro argiloso), Rolim \& Freire (1997) concluíram que esses foram marcadamente influenciados pelo tratamento com vinhaça.

Com este trabalho partiu-se da hipótese de que a vinhaça, alterando as cargas superficiais e a resistência de agregados à dispersão (Ribeiro et al., 2009), os limites de consistência (Freire \& Aguiar, 1993; Rolim \& Freire, 1997; Silva et al., 2006) e, também, podendo atuar como um fluído diferente à água, pode alterar atributos mecânicos do solo.

O tráfego de máquinas e equipamentos agrícolas para as operações de preparo do solo e colheita tem resultado na compactação de solos, sobretudo quando tais operações são realizadas em condições de umidade inadequadas (Severiano et al., 2008).

Neste trabalho teve-se ainda como hipótese que o estado de compactação do solo, sob influência ou não da vinhaça, pode afetar a erosão por salpicamento, primeira e mais importante fase do processo de erosão do solo (Hudson, 1995). Dessa forma, alterações na superfície podem afetar essa transferência de energia e, consequentemente, a quantidade de material salpicado.

Objetivou-se, com este trabalho, quantificar o efeito da vinhaça no comportamento compressivo e nos atributos mecânicos, como consistência, umidade ótima de compactação e densidade máxima, de um Latossolo Vermelho-Amarelo (LVA); avaliar o efeito da vinhaça e do estado de compactação no salpicamento de partículas.

\section{MATERIAL E MÉTODOS}

Foram coletadas amostras deformadas e indeformadas nas camadas de 0 a $3 \mathrm{~cm}$ e 60 a $63 \mathrm{~cm}$ de profundidade, representativas, respectivamente, dos horizontes A e Bw de um Latossolo Vermelho-Amarelo (LVA), sob pastagem natural, localizado no campus da Universidade Federal de Lavras, Lavras, MG. As amostras deformadas foram secas ao ar e destinaram-se à caracterização do solo, determinação dos limites de consistência e realização do ensaio de Proctor Normal. As amostras indeformadas foram coletadas em anéis de $6,35 \mathrm{~cm}$ de diâmetro e $2,5 \mathrm{~cm}$ de altura com auxílio do amostrador do tipo Uhland e destinaram-se aos ensaios de compressão uniaxial e resistência ao salpicamento em um minissimulador de chuvas. A caracterização do solo envolveu a determinação da composição granulométrica (Tabela 1), do complexo sortivo e o teor de óxidos do extrato sulfúrico (Tabela 2), de acordo com a metodologia da Empresa Brasileira de Pesquisa Agropecuária - Embrapa (1997).

A vinhaça foi proveniente de um alambique de cachaça artesanal localizado nas proximidades do município de Lavras, MG, a qual foi armazenada em câmara fria a $4^{\circ} \mathrm{C}$, para posterior caracterização e realização dos ensaios. $\mathrm{Na}$ Tabela 3 são apresentados alguns atributos químicos da vinhaça utilizada.

Para determinação dos limites de consistência, parte das amostras deformadas foram passadas em peneira de malha $2 \mathrm{~mm}$. Em seguida, $700 \mathrm{~g}$ de solo seco ao ar foram colocados em saco plástico e adicionada vinhaça o suficiente para atingir a capacidade de campo do solo (em média $0,30 \mathrm{~kg} \mathrm{~kg}^{-1}$ para as duas camadas estudadas) e mantido incubado por 48 horas. Após esse período, as amostras foram novamente secas ao ar, homogeneizadas, passadas em peneira de malha $0,42 \mathrm{~mm}$ e armazenadas para determinação dos limites de consistência. A determinação dos limites de consistência envolveu a determinação do limite de liquidez (LL), limite de plasticidade (LP) e limite de contração (LC), de acordo com a metodologia da Embrapa (1997).

A incubação do solo com vinhaça para realização do ensaio de Proctor Normal foi realizada da mesma forma descrita anteriormente, porém utilizando-se material passado em peneira de $4,76 \mathrm{~mm}$.

Tabela 1 - Composição granulométrica das camadas de 0-3 cm e 60-63 cm do Latossolo Vermelho-Amarelo (LVA).

\begin{tabular}{cccccccccc}
\hline \multirow{2}{*}{ Camada (cm) } & Argila & Silte & Areia & AMG & AG & AM & AF & AMF & Classificação textural \\
\hline $0-3$ & 499 & 166 & 335 & 49 & 72 & 88 & 102 & 24 & Argilosa \\
$60-63$ & 567 & 109 & 324 & 16 & 102 & 100 & 87 & 19 & Argilosa \\
\hline
\end{tabular}

AMG: areia muito grossa (2-1 mm); AG: areia grossa (1-0,5 mm); AM: areia média (0,5-0,25 mm); AF: areia fina $(0,25-0,105 \mathrm{~mm})$; AMF: areia muito fina $(0,105-0,053 \mathrm{~mm})$. 
Tabela 2 - Atributos químicos e mineralógicos das camadas de 0-3 cm e 60-63 cm do Latossolo VermelhoAmarelo (LVA).

\begin{tabular}{lcc}
\hline \multirow{2}{*}{ Atributos } & \multicolumn{2}{c}{ Camada $(\mathrm{cm})$} \\
\cline { 2 - 3 } & $0-3$ & $60-63$ \\
\hline $\mathrm{pH}$ em água & 5,7 & 5,3 \\
Matéria orgânica $\left(\mathrm{g} \mathrm{kg}^{-1}\right)$ & 31 & 21 \\
Soma de bases $\left(\mathrm{cmol}_{\mathrm{c}} \mathrm{dm}^{-3}\right)$ & 3,3 & 1,1 \\
$\mathrm{CTC}$ efetiva & 3,5 & 1,5 \\
$\mathrm{CTC}$ potencial & 8,1 & 7,4 \\
$\mathrm{Saturação} \mathrm{de} \mathrm{bases}(\%)$ & 41 & 15 \\
$\mathrm{SiO}_{2}{ }^{*}\left(\mathrm{~g} \mathrm{~kg}^{-1}\right)$ & 135 & 139 \\
$\mathrm{Al}_{2} \mathrm{O}_{3}{ }^{*}\left(\mathrm{~g} \mathrm{~kg}^{-1}\right)$ & 91 & 264 \\
$\mathrm{P}_{2} \mathrm{O}_{5}{ }^{*}\left(\mathrm{~g} \mathrm{~kg}^{-1}\right)$ & 1,2 & 0,6 \\
$\mathrm{TiO}_{2}{ }^{*}\left(\mathrm{~g} \mathrm{~kg}^{-1}\right)$ & 19 & 13 \\
$\mathrm{Fe}_{2} \mathrm{O}_{3}{ }^{*}\left(\mathrm{~g} \mathrm{~kg}^{-1}\right)$ & 90 & 91 \\
$\mathrm{Ki}$ & 2,53 & 0,90 \\
$\mathrm{Kr}^{\mathrm{Al}_{2} \mathrm{O}_{3} / \mathrm{Fe}_{2} \mathrm{O}_{3}}$ & 1,55 & 0,73 \\
\hline
\end{tabular}

* Óxidos do extrato sulfúrico; Ki: relação molecular $\left(\mathrm{SiO}_{2} / \mathrm{Al}_{2} \mathrm{O}_{3}\right)$; $\mathrm{Kr}$ : relação molecular $\left(\mathrm{SiO}_{2} / \mathrm{Al}_{2} \mathrm{O}_{3}+\mathrm{Fe}_{2} \mathrm{O}_{3}\right)$.

As amostras indeformadas foram saturadas por capilaridade durante 48 horas com vinhaça e água destilada (controle). Após esse período, as amostras foram equilibradas em laboratório em diferentes valores de umidade, sendo então submetidas ao ensaio de compressão uniaxial de acordo com Bowles (1986), modificado por Dias Júnior \& Pierce (1995).

Para o ensaio de salpicamento, as amostras indeformadas previamente saturadas com vinhaça ou água destilada (controle) por 48 horas foram equilibradas no extrator de placas porosas: $15 \mathrm{~atm}$ e 0,33 atm. As amostras saturadas e com umidade equivalente às tensões supracitadas foram submetidas ao ensaio de compressão uniaxial aplicando-se as pressões de 50 e $400 \mathrm{kPa}$ (Soane, 1986). Logo após, as amostras foram submetidas ao impacto de gotas de chuva simulada, de diâmetro 2,45 mm, intensidade de $150 \mathrm{~mm} \mathrm{~h}^{-1}$, durante 8 minutos, utilizandose um mini-simulador de chuva (Ribeiro et al., 2009). A chuva simulada aplicada teve uma energia cinética total de 3,79 $\mathrm{MJ} \mathrm{ha}^{-1}$ (Ribeiro et al., 2009), com um tempo de retorno de dez anos para a cidade de Lavras, MG (Mello et al., 2001). Todo o material salpicado durante a chuva foi recolhido, seco em estufa a $105^{\circ} \mathrm{C}$ por 48 horas e relacionado com a área da amostra, expressando-se o resultado em $\mathrm{Mg} \mathrm{ha}^{-1}$. Os resultados foram interpretados e discutidos baseados no desvio padrão da média $(n=3)$.

Os valores de pressão de preconsolidação foram plotados em função das diferentes umidades, para a obtenção dos modelos de capacidade suporte de cargas do solo. As equações de regressão (modelos de sustentabilidade da estrutura) foram obtidas utilizando-se o programa SigmaPlot 10.0 e as comparações das regressões foram realizadas segundo procedimentos descritos em Snedecor \& Cochran (1989), o qual permite testar as equações fornecidas através do Excel.

\section{RESULTADOS E DISCUSSÃO}

Na camada de 0-3 cm observa-se que o tratamento com vinhaça reduziu o limite de plasticidade (LP) e também a faixa friável (LP - LC) (Figura 1). Em um Latossolo Vermelho, textura média, foi observado que a vinhaça aumentou o LP e LL (Camargo et al., 1983), atribuído ao aumento do teor de matéria orgânica do solo.

A vinhaça tem alta concentração de $\mathrm{K}$ e pode elevar sobremaneira a concentração desse elemento no complexo de troca e na solução do solo. Ohtsubo et al. (1983) observaram que o limite de liquidez correlacionou-se positivamente com a capacidade de troca de cátions e com a quantidade de cátions presentes na solução do solo. Resultados semelhantes também foram observados por Arasan \& Yetimoglu (2008), porém trabalhando com amostras da fração argila.

Tabela 3 - Caracterização química da vinhaça.

\begin{tabular}{|c|c|c|c|c|c|c|c|}
\hline $\mathrm{pH}^{*}$ & $\mathrm{CE}^{*}$ & $\mathrm{CO}^{* *}$ & $\mathrm{~N}^{* * * *}$ & $\mathrm{P}^{* * *}$ & $\mathrm{~K}^{* * *}$ & $\mathrm{Ca}^{* * *}$ & $\mathrm{Mg}^{* * *}$ \\
\hline & $\mathrm{dS} \mathrm{m}^{-1}$ & & ----. & - & 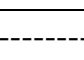 & -- & \\
\hline 3,0 & 5,7 & 2,86 & 0,98 & 0,69 & 1,84 & 0,01 & 0,7 \\
\hline
\end{tabular}

"pH e condutividade elétrica (CE), determinados diretamente na vinhaça in natura ; ${ }^{* *}$ carbono orgânico: determinado após digestão de $0,5 \mathrm{~mL}$ de vinhaça com dicromato de potássio e titulação com sulfato ferroso amoniacal; ${ }^{* * *}$ determinados no extrato após digestão nitroperclórica de $5 \mathrm{~mL}$ de vinhaça; $\mathrm{N}$ : titulação; P: colorimetria; K: fotômetro de chama; $\mathrm{Ca}$ e Mg: absorção atômica de chama. 


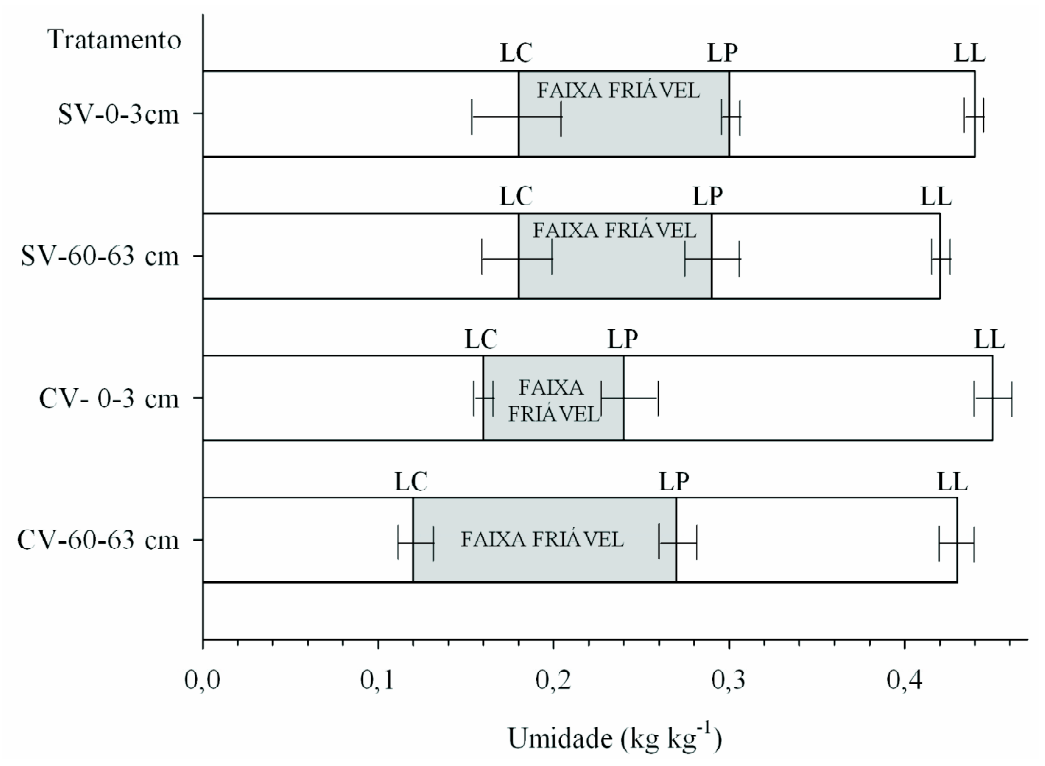

Figura 1 - Efeito da vinhaça nos limites de consistência das camadas 0-3 cm e 60-63 cm do Latossolo Vermelho-Amarelo (LVA). LL: limite de liquidez: LP: limite de plasticidade: LC: limite de contração; faixa friável = LP - LC; SV: sem vinhaça; $\mathrm{CV}$ : com vinhaça.

Para a camada de $60-63 \mathrm{~cm}$ foi observada uma redução do LC com o tratamento com vinhaça, o que contribuiu para um aumento da faixa friável. A faixa friável é considerada um intervalo adequado para o preparo do solo e tráfego de máquinas. A sua redução, como observada para a camada de 0-3 cm, implica em menor tempo disponível para as operações de preparo sem que haja problemas de compactação. Contudo, a utilização da faixa de friabilidade, como tomada de decisão no momento das operações de preparo do solo e colheita, por exemplo, pode não ser a mais correta, haja vista que, mesmo na faixa de friabilidade, a compactação do solo pode ocorrer (Kondo \& Dias Júnior, 1999).

Na Figura 2 são apresentados os valores da densidade do solo em função da umidade obtidos do ensaio de Proctor Normal. Observa-se que a camada de 0-3 cm, sem vinhaça, apresentou menor $\mathrm{D}_{\text {máx }}$ e maior $\mathrm{U}_{\text {ótima }}$ comparativamente à camada de $60-63 \mathrm{~cm}$. Tais diferenças podem estar relacionadas ao maior conteúdo de matéria orgânica da camada de 0-3 cm (Tabela 2), atenuando os impactos do processo de compactação e não permitindo a orientação das partículas minerais do solo (Dias Júnior \& Miranda, 2000; Silva \& Cabeda, 2006). Em ambas as camadas, o tratamento com vinhaça aumentou a $\mathrm{D}_{\text {máx }} \mathrm{e}$ reduziu a $\mathrm{U}_{\text {ótima }}$. A vinhaça pode ter atuado como um fluido diferente da água, facilitando a organização das partículas. Tais resultados alertam para o fato de que esse solo pode sofrer compactação máxima, mesmo quando trabalhado com baixos teores de água, carecendo de maiores cuidados, durante as atividades com máquinas agrícolas (preparo do solo e colheita da cana-de-açúcar).

Os efeitos da vinhaça sobre parâmetros mecânicos do solo variam com as doses empregadas e com o material de solo utilizado. Em um solo de textura areno-argilosa, a aplicação de vinhaça concentrada a $30 \%$ a razão de 0,23 e $0,30 \mathrm{dm}^{3}$, por $\mathrm{kg}$ de solo, não teve efeito sobre os parâmetros $D_{\text {máx }}$ e $U_{\text {ótima }}$ (Silva \& Freire, 1992). Em dois solos de textura contrastantes, um areno-argiloso e outro argilosiltoso, a aplicação de vinhaça reduziu significativamente a $\mathrm{D}_{\text {máx }}$ e aumentou a $\mathrm{U}_{\text {ótima }}$ (Freire \& Aguiar, 1993).

Com exceção da camada de $0-3 \mathrm{~cm}$ com vinhaça, os valores de $\mathrm{U}_{\text {ótima }}$ encontrados (Figura 2) estão na faixa friável (Figura 1). Isso significa que mesmo estando na faixa friável, se o solo for submetido a uma energia de compactação semelhante à imposta pelo ensaio de Proctor Normal, a compactação máxima pode ser atingida.

Os modelos de capacidade suporte de carga ajustados para cada uma das condições não foram estatisticamente diferentes (Tabela 4). Diante disso, foi gerado um único modelo para o LVA, apresentado na Figura 3.

O modelo de suporte de carga pode ser usado na predição do comportamento compressivo do solo em diferentes situações. Como exemplo, a camada 0-3 cm sem 

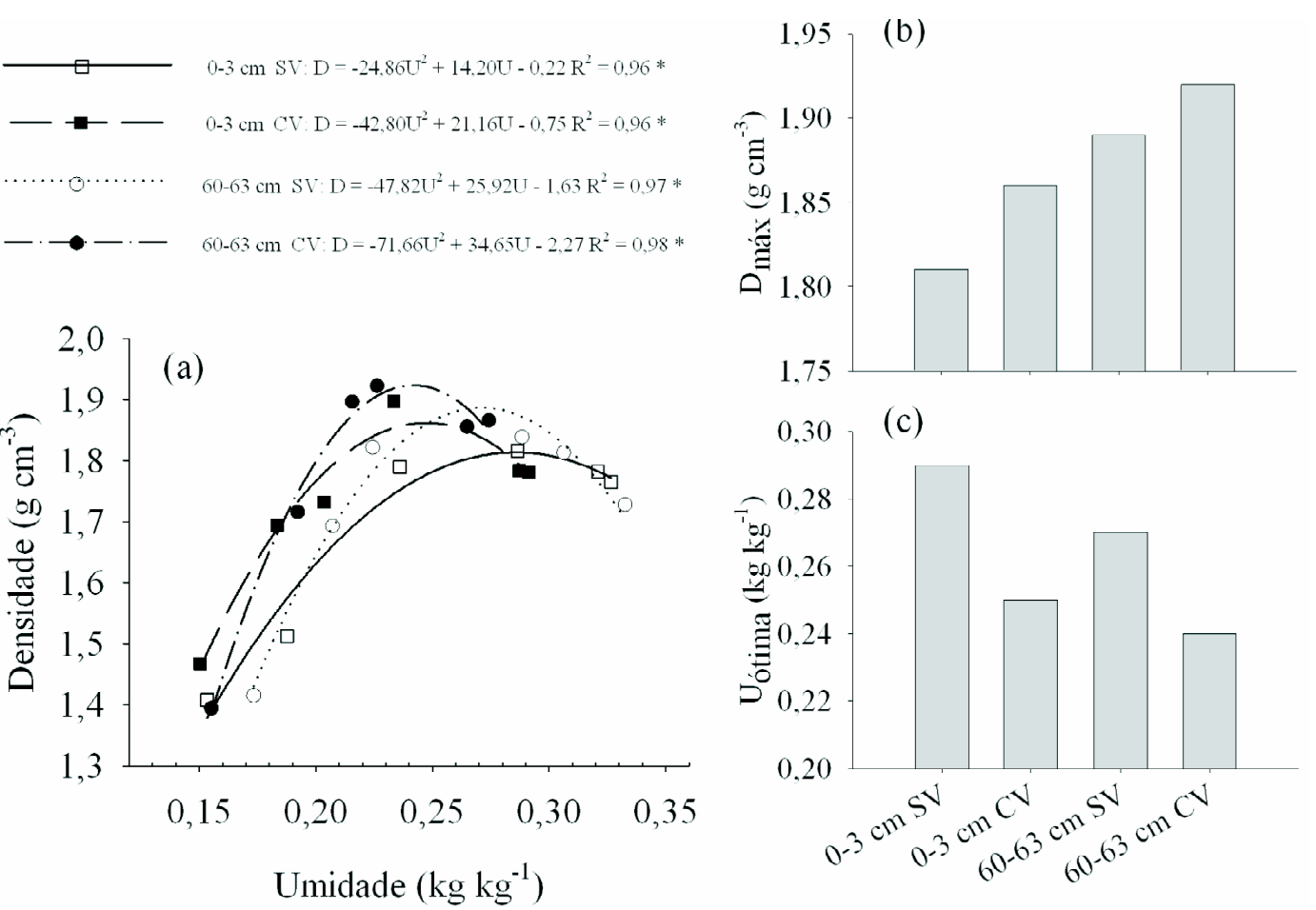

Figura 2 - Curvas de compactação do ensaio de Proctor Normal para as camadas 0-3 cm e 60-63 cm do Latossolo Vermelho-Amarelo (LVA), sob influência da vinhaça (a). densidades máximas $\left(\mathrm{D}_{\text {máx }}\right)$ (b) e umidades ótimas de compactação $\left(\mathrm{U}_{\text {ótima }}\right.$ ) (c). SV e CV, sem e com vinhaça, respectivamente; * p<0,01 (Teste F).

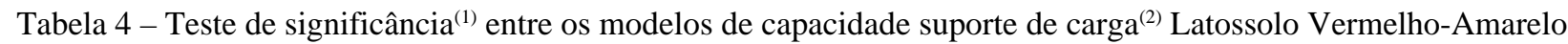
(LVA), sob pastagem com e sem a aplicação de vinhaça em duas profundidades.

\begin{tabular}{|c|c|c|c|c|}
\hline \multirow{2}{*}{ Condição } & \multirow{2}{*}{ Profundidade $(\mathrm{cm})$} & \multirow{2}{*}{$\mathrm{F}$} & \multicolumn{2}{|c|}{$\mathrm{F}$} \\
\hline & & & Coeficiente angular, b & Intercepto da regressão, a \\
\hline Sem vinhaça & $0-3 \times 60-63$ & $\mathrm{H}$ & ns & ns \\
\hline Com vinhaça & $0-3 \times 60-63$ & $\mathrm{H}$ & ns & ns \\
\hline $\begin{array}{c}\text { Sem vinhaça X Com } \\
\text { vinhaça }\end{array}$ & $\begin{array}{c}0-3 \text { e } 60-63 X \\
0-3 \text { e } 60-63\end{array}$ & $\mathrm{H}$ & ns & ns \\
\hline
\end{tabular}

vinhaça suporta uma pressão máxima, sem haver compactação adicional, de 298 e $207 \mathrm{kPa}$ nos limites de contração (LC) e plasticidade (LP), respectivamente (Tabela 5). A vinhaça alterou esses limites (Figura 1), o solo passou a suportar mais carga, 316 e $249 \mathrm{kPa}$ no LC e LP, respectivamente. No entanto, a redução da faixa friável com a aplicação de vinhaça (Figura 1) implica em uma menor faixa de pressão máxima suportada pelo solo, limitando a trafegabilidade.

$\mathrm{Na}$ condição sem vinhaça, na profundidade de 0-3 cm, a faixa friável apresenta um intervalo de $91 \mathrm{kPa}$, enquanto na condição com vinhaça esse valor foi reduzido para $67 \mathrm{kPa}$ (Tabela 5). Com o uso de vinhaça nessas condições, a capacidade suporte de cargas do solo diminuiu e consequentemente tornou-o mais susceptível à compactação. Para a camada $60-63 \mathrm{~cm}$ observa-se um aumento da sp nos LC e LP, com a adição de vinhaça. Entretanto, como a faixa friável foi aumentada (Figura 1), o intervalo na sp foi aumentado de $85 \mathrm{kPa}$ para $130 \mathrm{kPa}$, nas condições sem e com vinhaça, respectivamente. 


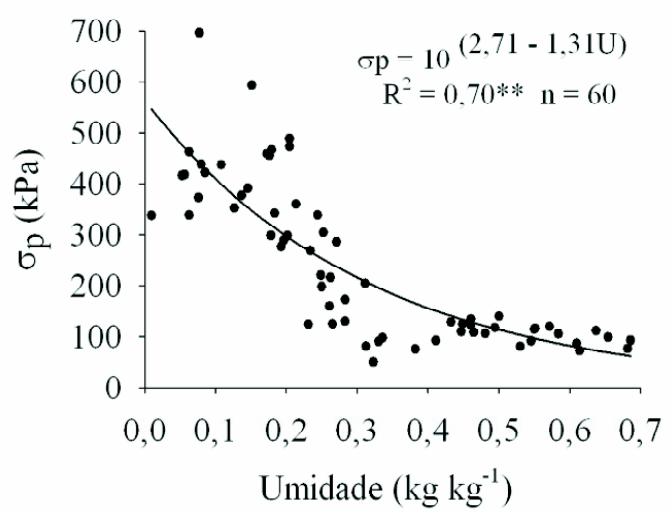

Figura 3 - Modelo de suporte de carga para o Latossolo Vermelho-Amarelo (LVA), independentemente da camada e do tratamento com vinhaça.

$\mathrm{Na}$ Figura 4, observa-se que na camada de $0-3 \mathrm{~cm}$, independentemente do tratamento e da umidade da amostra, houve um aumento na quantidade de material salpicado com as pressões aplicadas, principalmente em $400 \mathrm{kPa}$. Observa-se ainda, que os valores de densidade não se alteraram significativamente, o que implica em dizer que, para as pressões aplicadas, as amostras ainda estão na faixa de compressão secundária, caracterizada por deformações elásticas e recuperáveis (Dias Júnior \& Pierce, 1995, 1996). O aumento na quantidade de material salpicado com a pressão aplicada pode estar relacionado com a quebra de agregados nos primeiros milímetros das amostras, desestruturando e facilitando o salpicamento.

A ocorrência de maior salpicamento nas amostras compactadas pode estar relacionada ainda com as modificações da superfície das amostras. Com a aplicação de cargas na superfície ocorre uma quebra e reorganização dos agregados, com o aumento da densidade e redução do espaço poroso nos primeiros milímetros (Schäffer et al., 2007, 2008). Isso torna a superfície das amostras menos rugosas dificultando a dissipação da energia proveniente do impacto das gotas de chuva. As gotas de chuva ao colidirem com o solo têm sua energia cinética transformada em energia de cisalhamento, o que leva ao salpicamento das partículas (Al-Durrah \& Bradford, 1982). Nas amostras não compactadas a rugosidade da superfície ajuda a dissipar parte dessa energia.

Condições de superfície também têm efeito sobre o ângulo de salpicamento das partículas. Em condições não compactadas e de maior rugosidade em superfície, as partículas tendem a serem salpicadas mais verticalmente, formando ângulos próximos de $45^{\circ}$ com a superfície. Já em condições compactadas, as partículas são salpicadas mais horizontalmente, ou seja, mais rasantes com a superfície (Al-Durrah \& Bradford, 1982).

Na camada de $60-63 \mathrm{~cm}$, o aumento na quantidade de material salpicado aconteceu apenas na condição sem vinhaça, provavelmente pela mesma razão levantada anteriormente, um rompimento da estrutura natural das amostras nos primeiros milímetros. Quando as amostras foram tratadas com vinhaça, o aumento na quantidade de material salpicado com as pressões aplicadas não foi observado e até mesmo diminuiu quando as amostras foram equilibradas com umidade na capacidade campo. Nesse caso, a vinhaça parece ter contribuído para uma maior estabilidade de agregados na superfície das amostras e, consequentemente, reduzindo a quantidade de material salpicado.

Tabela 5 - Pressão de pré-consolidação ( $\sigma \mathrm{p})$ nas umidades equivalentes ao limite de contração (LC) e plasticidade (LP) e intervalo de $\sigma \mathrm{p}$ na faixa friável para as camadas $0-3 \mathrm{~cm}$ e $60-63 \mathrm{~cm}$ do Latossolo Vermelho-Amarelo (LVA), sob influência da vinhaça.

\begin{tabular}{cccc}
\hline Camada $(\mathrm{cm})$ & LC & LP & ${\text { Faixa friável }(\mathrm{LP}-\mathrm{LC})^{*}}^{*}$ \\
\hline $0-3 \mathrm{SV}$ & $298( \pm 42)$ & $207( \pm 7)$ & $91( \pm 49)$ \\
$0-3 \mathrm{CV}$ & $316( \pm 5)$ & $249( \pm 27)$ & $67( \pm 25)$ \\
$60-63 \mathrm{SV}$ & $298( \pm 35)$ & $213( \pm 22)$ & $85( \pm 27)$ \\
$60-63 \mathrm{CV}$ & $357( \pm 16)$ & $227( \pm 10)$ & $130( \pm 18)$ \\
\hline
\end{tabular}

"Diferença dos valores de $\sigma p$ no LC e LP; SV e CV, sem e com vinhaça, respectivamente; Valores de $\sigma p$ estimados com base no modelo $\left[\sigma p=10^{(2,71-1,31 \mathrm{U})}\right.$ (Figura 4), em que U é a umidade nos limites de contração (LC) ou plasticidade (LP); Valores entre parênteses indicam o desvio-padrão da média $(\mathrm{n}=3)$. 
Ponto de murcha permanente

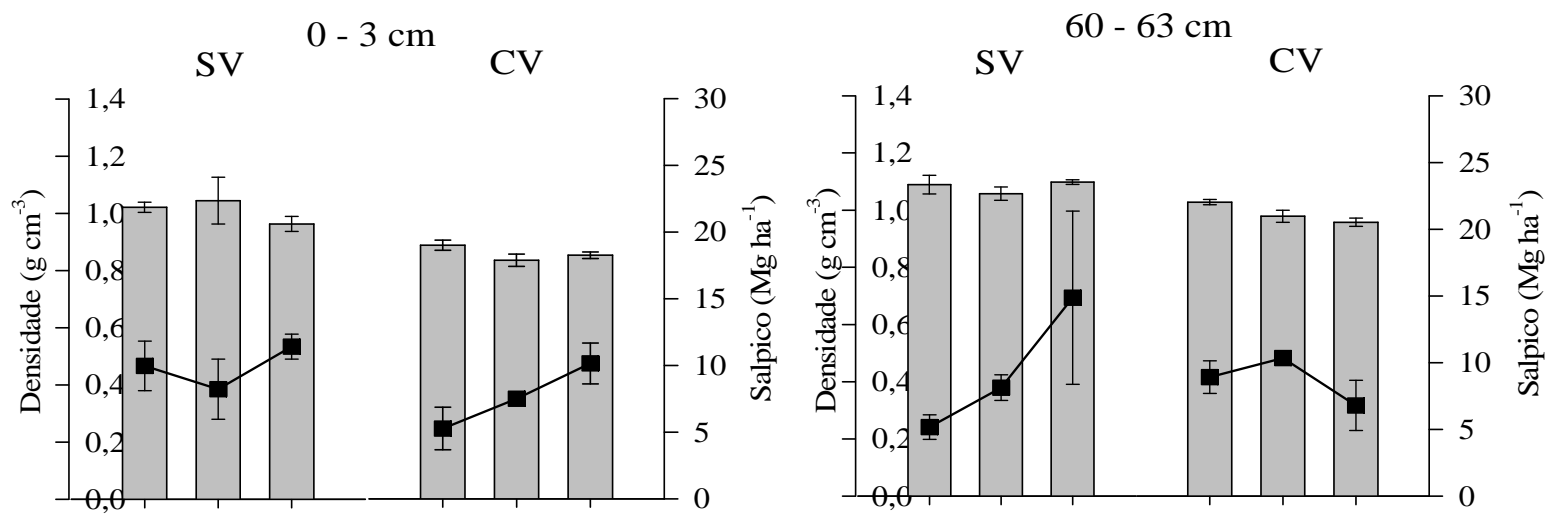

Capacidade de campo

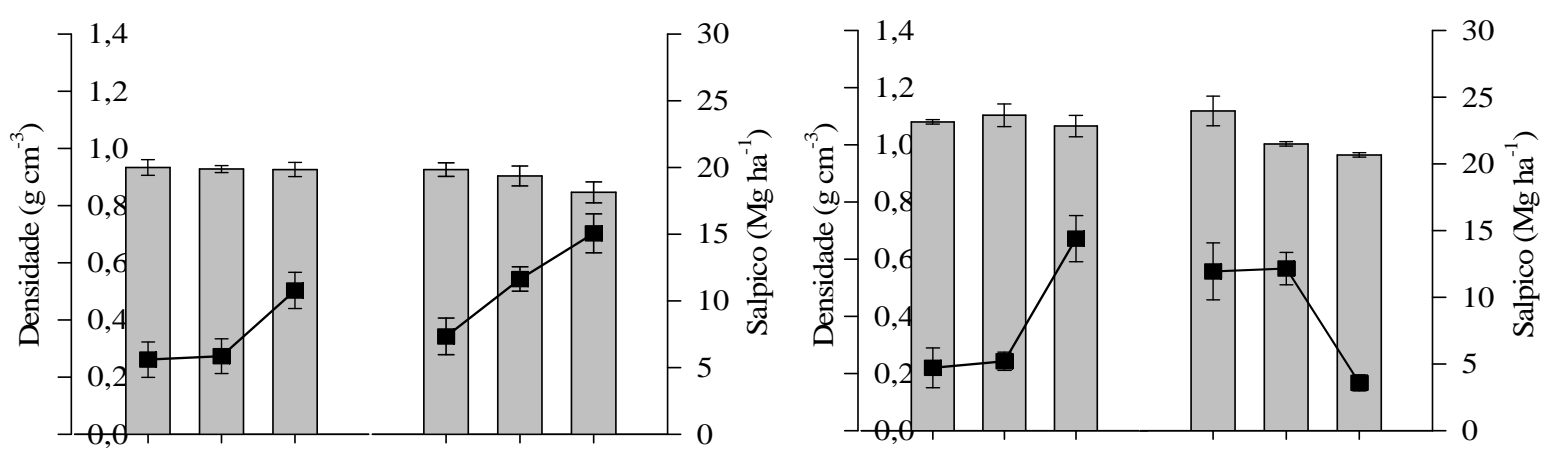

Umidade de saturação

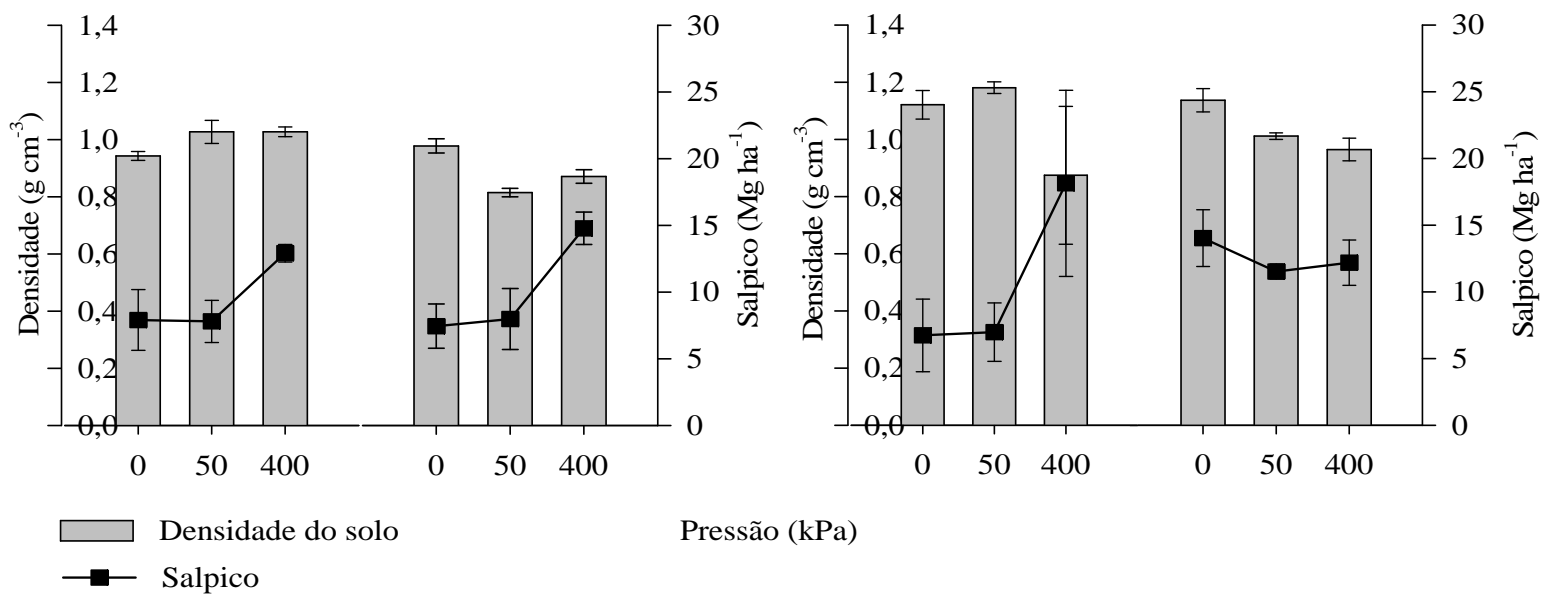

Figura 4 - Efeito das pressões aplicadas na superfície das amostras sobre a densidade e quantidade de material salpicado, das camadas 0-3 cm e 60-63 cm do Latossolo Vermelho-Amarelo (LVA), sob influência da vinhaça. SV e CV, sem e com vinhaça, respectivamente; Barras de erro verticais indicam o desvio-padrão da média $(n=3)$. 


\section{CONCLUSÕES}

A vinhaça alterou os limites de consistência das camadas de solo estudadas, aumentou a $\mathrm{D}_{\text {máx }}$, reduziu a $\mathrm{U}_{\text {ótima }}$, porem sem influenciar a capacidade suporte de carga do solo.

O estado de compactação e o teor de umidade das amostras influenciam a erosão por salpicamento. Amostras mais compactadas foram mais susceptíveis ao salpicamento, atribuindo-se ao rompimento dos agregados na superfície da amostra e, também, à redução da rugosidade superficial.

Esses resultados alertam para o fato de que esse solo, nas condições trabalhadas, pode sofrer compactação máxima, carecendo de maiores cuidados durante o preparo do solo e a colheita mecanizada.

\section{AGRADECIMENTOS}

À Fundação de Amparo à Pesquisa de Minas Gerais Fapemig, pela aprovação dos recursos financeiros do projeto (Protocolo 2722/06) e ao CNPq e Capes, pela concessão de bolsas aos autores.

\section{REFERÊNCIAS BIBLIOGRÁFICAS}

AL-DURRAH, M.M.; BRADFORD, J.M. The mechanism of raindrop splash on soil surfaces. Soil Science Society of America Journal, Madison, v.46, n.5, p.1086-1090, Sept./Oct. 1982.

ANDRIETTA, M.G.S.; ANDRIETTA, S.R.; STECKELBERG, C.; STUPIELLO, E.N.A. Bioethanol: Brazil, 30 years of Proalcool. International Sugar Journal, v.109, p.195-200, 2007.

ARASAN, S.; YETIMOGLU, T. Effect of inorganic salt solutions on the consistency limits of two clays.

Turkish Journal Engineering Environmental Science, v.32, p.107-115, 2008.

BOWLES, J.E. Engineering properties of soils and their measurements. 3.ed. Auckland: McGraw-Hill, 1986. $218 \mathrm{p}$.

CAMARGO, O.A.; VALADARES, J.M.A.S.; GERALDI, R.N. Características químicas e físicas de solo que recebeu vinhaça por longo tempo. Campinas: Instituto Agronômico, 1983. 30p. (Boletim técnico, 76).

CARDOSO, M.G. (Ed.). Produção de aguardente de cana. 2.ed. Lavras: UFLA, 2006. 445p.
DIAS JÚNIOR, M. de S.; MIRANDA, E.E.V. Comportamento da curva de compactação de cinco solos da região de Lavras (MG). Ciência e Agrotecnologia, Lavras, v.24, n.2, p.337-346, abr./jun. 2000.

DIAS JÚNIOR, M. de S.; PIERCE, F.J. Revisão de literatura: o processo de compactação do solo e sua modelagem. Revista Brasileira de Ciencia do Solo, Campinas, v.20, n.1, p.175-182, jan./fev. 1996.

DIAS JÚNIOR, M. de S.; PIERCE, F.J. A simple procedure for estimating preconsolidation pressure from soil compression curves. Soil Technology, London, v.8, p.139-151, 1995.

\section{EMPRESA BRASILEIRA DE PESQUISA} AGROPECUÁRIA. Manual de métodos de análise de solo. 2.ed. Rio de Janeiro: CNPS, 1997. 212p.

FREIRE, W.J.; AGUIAR, M.A. Incorporação de vinhaça concentrada em dois solos distintos: caracteríscticas químicas, físicas e mecânicas da mistura obtida. Engenharia Agrícola, Jaboticabal, v.13, p.85-96, 1993.

FREIRE, W.J.; CORTEZ, L.A.B. Vinhaça de cana-deaçúcar. Guaíba: Agropecuária, 2000. 203p.

GOLDEMBERG, J. The Brazilian biofuels industry. Biotechnology for Biofuels, v.1, n.6, p.1-7, May 2008.

HUDSON, N. Soil conservation. 3.ed. Ames: Iowa State University, 1995. 391p.

KONDO, M.K.; DIAS JÚNIOR, M.S. Compressibilidade de três latossolos em função da umidade e uso. Revista Brasileira de Ciência do Solo, Viçosa, v.23, p.211-218, 1999.

MELLO, C.R.; FERREIRA, D.F.; SILVA, A.M.; LIMA, J.M. Análise de modelos matemáticos aplicados ao estudo de chuvas intensas. Revista Brasileira de Ciência do Solo, Viçosa, v.25, n.3, p.693-698, jul./set. 2001.

OHTSUBO, M.; TAKAYAMA, M.; EGASHIRA, K. Relationships of consistency limits and activity to some physical and chemical properties of Ariake Marine clays. Soils and Foundations, v.23, n.1, p.3846, Mar. 1983. 
RIBEIRO, B.T.; LIMA, J.M.; MELLO, C.R.; SÁ, M.A.C.; OLIVEIRA, G.C. Relationship between raindrops and ultrasonic energy on the disruption of a haplic cambisol. Ciência e Agrotecnologia, Lavras, v.33, n.3, p.814-823, maio/jun. 2009.

ROLIM, M.M.; FREIRE, W.J. Efeito da vinhaça concentrada sobre a estabilidade estrutural dos agregados do solo. Engenharia Agrícola, Jaboticabal, v.16, n.3, p.69-76, mar. 1997.

SCHÄFFER, B.; STAUBER, M.; MUELLER, T.L.; MÜLLER, R.; SCHULIN, R. Soil and macro-pores under uniaxial compression: I., mechanical stability of repacked soil and deformation of different types of macro-pores.

Geoderma, Amsterdam, v.146, p.183-191, 2008.

SCHÄFFER, B.; STAUBER, M.; MÜLLER, R.; SCHULIN, $R$. Changes in the macro-pore structure of restored soil caused by compaction beneath heavy agricultural machinery: a morphometric study. European Journal of Soil Science, London, v.58, p.1062-1073, Oct. 2007.

SEVERIANO, E.C.; OLIVEIRA, G.C.; DIAS JÚNIOR, M. de S.; OLIVEIRA, L.F.C.; CASTRO, M.B. Pressão de preconsolidação e intervalo hídrico ótimo como indicadores de alterações estruturais de um Latossolo e de um Cambissolo sob cana-de-açúcar. Revista Brasileira de Ciencia do Solo, Viçosa, v.32, p.1419-1427, 2008.

SILVA, A.J.N.; CABEDA, M.S.V. Compactação e compressibilidade do solo sob sistemas de manejo e níveis de umidade. Revista Brasileira de Ciência do Solo, Viçosa, v.30, p.921-930, 2006.

SILVA, A.J.N.; CABEDA, M.S.V.; CARVALHO, F.G. Matéria orgânica e propriedades físicas de um Argissolo Amarelo Coeso sob sistemas de manejo com cana-deaçúcar. Revista Brasileira de Engenharia Agrícola e Ambiental, Campina Grande, v.10, n.3, p.579-586, 2006.

SILVA, E.T.; FREIRE, W.J. Caracterização físico-mecânica de um solo tratado com vinhaça. Agrárias, v.12, n.1/2, p.7-12, 1992.

SOANE, B.D. Process of soil compaction under vehicular traffic and means of alleviating it. In: LAL, R. et al. (Ed.). Land clearing and development in the tropics. Rotterdam: Balkema, 1986. p.265-297. 